\title{
The development of interspecies social attachments'
}

\author{
Robert B. Cairns and Donald L. Johnson \\ INDIANA UNIVERSITY
}

\begin{abstract}
Strong cross-species social attachments were produced by confining young lambs with canine cohabitants. The reinforcement properties of the attachment, and the conditions for its reversal, were determined.
\end{abstract}

\section{Problem}

Studies of immature mammals have demonstrated the significant effects of prolonged isolation on the development of social responses. One of the most interesting observations has been that animals reared in isolation later exhibit asocial response patterns, i.e., they remain aloof from members of their species even when opportunities for interaction become available (Harlow, 1962; Scott, 1962).

Discussions of this phenomenon have typically focussed upon the negative features of the experimentally produced environments; namely, the absence of social stimuli which are normally present. It seems reasonable to propose; however, that some attention should be given to the cues that are available in the "isolation" setting. Not only have "isolated" animals been deprived of interaction experiences, but equally important, they have been exposed to different patterns of environmental cues. Certain of these cues, by virtue of their saliency and constancy, might be expected to take on significant elicitory and discriminatory properties for the developing organism.

The present interspecies rearing experiment was conducted to test one implication of the above proposal. It was expected that extended isolation of a young lamb from contact with other sheep, coupled with continuous exposure to an animal of an alien species, would significantly alter the cue properties of the latter animal. After a period of continuous confinement, then, the abrupt removal of the cohabitant (alien animal) should be correlated with significant behavioral disruption; and the cohabitant's return should be associated with a cessation of disruption. It would also follow that the lamb would acquire responses which were instrumental to reinstating the presence of the cohabitant.

\section{Method}

Eight Dorset lambs served as Ss; four Rambouillet ewes and four mature female collies were cohabitants. The lambs were 12-13 weeks old at the beginning of the experimental confinement.

Lambs were assigned at random to a ewe or canine. The resultant pairs were confined together for $24 \mathrm{hr}$. a day over 105 days. Each of the eight living compartments was $8 \mathrm{ft} \times 10 \mathrm{ft}$, enclosed on all sides. During this period the lambs were permitted no contact with other animals. While the ewe-lamb pairs were permitted to interact without restriction, three of the four canine-lamb pairs were continuously separated: the lamb was placed on one side of a wire fence which extended down the midline of the compartment and the dog on the other. This procedure was followed because three of the canines had attacked the lambs with which they had been paired. The separations were completed during the first week of confinement.
After $63( \pm 2)$ days of confinement, the eight lambs were tested in the U-maze. In the first, the non-contrast series, one goal compartment was empty and the other contained the animal with which the lamb had been housed. Prior to the first test trial, each lamb was forced twice to either goal area. The non-correction method was used in the regular test series: as soon as the lamb entered either arm, a guillotine door was dropped, and the lamb was enclosed in the goal area for $60 \mathrm{sec}$. Testing continued until the lamb made 10 consecutive runs to the goal area where the cohabitant was tethered.

A second series of learning trials was conducted on day $72( \pm 2)$. In this, the contrast series, a ewe was placed in one goal area, and a canine in the other. One of these animals was the lamb's cohabitant. The position occupied by the cohabitant was opposite its placement in the previous series. The lambs were again given four forced runs, two to either side, prior to the first test trial. Two additional forced runs were interspersed between trials 10 and 11 . Twenty consecutive test trials were run.

The final series of tests was conducted after $105( \pm 2)$ days of confinement. Each lamb was observed over a series of trials where the cohabitant was removed from the compartment, then reintroduced. The removal-replacement alternation sequence was continued until 11 observations of $60 \mathrm{sec}$. duration had been obtained for each lamb. The measure of behavioral disturbance recorded was the frequency of vocalizations, i.e., number of bleats per minute emitted by the lamb.

The U-maze was of plywood and wire construction. Thirty-in wide runways were enclosed by $4 \mathrm{ft}$ plywood walls, and covered by translucent netting material. The dimensions of the runway segments were: start compartment to choice point, $12 \mathrm{ft}$; choice point to turn, $7 \mathrm{ft}$; turn to goal area, $4 \mathrm{ft}$. The goal areas were $8 \mathrm{ft} \times 8 \mathrm{ft}$. Guillotine doors were located in the start compartment, and on either side of the choice point.

\section{Results}

Non-contrast learning trials: All the animals learned rapidly, committing few errors prior to reaching criterion. A comparison of the error scores indicated no difference between the lambs assigned to the ewes and those assigned to the canines. Indeed, the lambs in the interspecies condition made somewhat fewer (nonsignificantly) errors than those paired with the ewes: mean errors, 3.0 and 4.8, respectively. The lambs' behavior upon reaching the empty goal compartment on "error" trials is of some interest: the animals bleated, repeatedly and vigorously, and paced in an agitated fashion. These behaviors were rarely observed when the lamb entered the goal area of its cohabitant (mean bleats in goal compartment: empty =16.08; cohabitant $=.99$ ). Typically the lamb approached and remained close to his cohabitant.

Contrast learning trials: Figure 1 summarizes these results. Clearly the lambs acquired responses which were instrumental to reaching the animal with which they had been housed, regardless of its species. The distributions of choices of the two groups of lambs were non-overlapping $(t=7.83 ; \mathrm{df}=6 ; \mathrm{p}<.001)$ 。

Removal-replacement of cohabitant: The lamb's repeated bleating formed one significant part of the general pattern of behavior disorganization that 


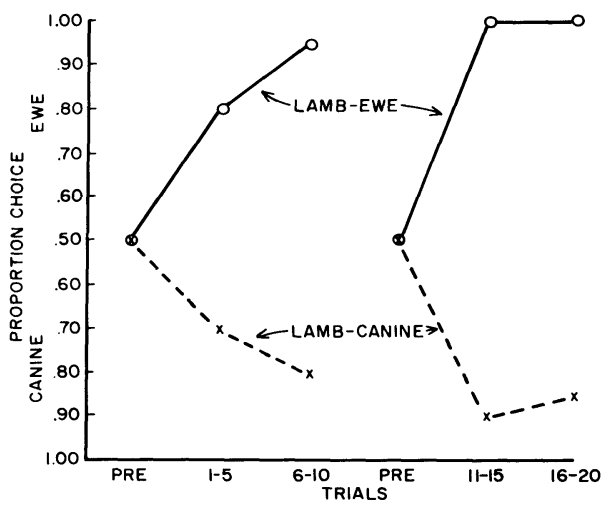

Fig. 1. U-maze performance of canine-paired and ewe-paired lambs in the contrast series.

could be observed when the cohabitant was removed from the living compartment. Correlated behaviors included agitated pacing, jumping against the walls, and pushing the compartment door. A perfect contingency was obtained between vocalization and the absence of the cohabitant (bleats $/ \mathrm{min}$. present $=0.00$; bleats $/ \mathrm{min}$. absent $=17.3$ ). The difference between pairing conditions was not significant.

Following response: One of the most striking response patterns observed was the development of a strong following response by the lambs. Scott (1945) has noted that orphaned lambs developed such a response to their human caretakers. In the present experiment, however, every lamb exhibited a marked following response with respect to its cohabitant by the 9 th week of pairing.

Reversibility of interspecies preference: After 106 days of confinement, all of the lambs were returned to the breeder from whom they had been originally acquired. 2 These animals were placed with a small flock of sheep reared under normal conditions. After four months, the three surviving canine-paired animals were returned to the laboratory and given a series of 20 contrast trials. The choice objects were the original cohabitant and another sheep. In the final block of 10 trials, the lambs selected the canine on only 2 of the 30 trials (7\%). Apparently an extended cohabitation with the same species was sufficient to reverse the experimentally produced preference.

\section{Diseussion}

Recent investigators (Denenberg etal, 1964; Hersher, Richmond, \& Moore, 1963) have reported the formation of interspecies attachments, e.g., mouse-rat, sheepgoat, following the animals' participation in crossspecies fostering experiences. The present data extend these findings in demonstrating that remarkably strong interspecies attachments can be produced even when the animals have not been involved in extensive physical interaction. These data, it should be noted, suggest limitations on the generality of recent theoretical accounts of mammalian attachment behavior (Harlow \& Zimmerman, 1959; Gerwirtz, 1961).

Scott (1962) has proposed the empirical generalization that a mammal will develop an attachment toward any object to which it is continuously exposed. While our data are generally consistent with that generalization, it should be noted that the lambs in the present study became attached to the animate objects in their immediate environment, and not to the equally available inanimate ones. As both the removal trials and the learning series indicate, the social preferences which developed were discriminant and specific, not general and contextual.

It seems reasonable to suggest that Scott's generalization be amended to account for the apparent selectivity of attachment behavior. It would be consistent with the available evidence, as well as with theories of associative learning, to propose that highly salient stimuli are more likely to acquire elicitory and discriminatory properties than are less salient events. Accordingly, animals, because of their relatively greater conspicuousness and prominence, would be more likely to become the focus of an attachment response than would non-living objects. It would follow that the various stimulus characteristics of objects that have been shown to facilitate attachment formation, e.g., lactation, softness and warmth, etc., are effective because they enhance the salience of the object, and not because of presumed hedonic properties.

\section{References}

DENENBERG, V. H., HUDGENS, G. A., \& ZARROW, M.X. Mice reared with rats: modification of behavior by early experience with another specis. Science, 1964, 143, 380-381.

GEWIRTZ, J. L. A learning analysis of the effects of normal stimulation, privation, and deprivation on the acquisition of social motivation and attachment. In B. M. Foss (Ed.), Determinants of infant behavior. New York: Wiley, 1961.

HARLOW, H. F. The heterosexual affectional system in monkeys. Amer. Psychologist, 1962, 17, 1-9.

HARLOW, H. F., \& ZIMMERMAN, R. R. Affectional responses in the infant monkey. Science, 1959, 130, 421-432.

HERSHER, L., RICHMOND, J. B., \& MOORE, A. U. Modifiability of the critical period for the development of maternal behavior in sheep and goats. Behavior, 1963, 20, 311-320.

SCOTT, J. P. Social behavior, organization, and leadership in a small flock of domestic sheep. Comp. Psychol. Monogr., 1945, 18, 1-29. SCOTT, J. P. Critical periods in behavioral development. Science, 1962, 138, 949-958.

Notes

1. This research was supported in part by USPHS grant 08757-01 and reported at the 1964 APA meetings, Los Angeles. Roy Webb provided invaluable assistance in the conduct of this work.

2. Spring Hill Stock Farms, Greenwood, Indiana. 